\title{
Survey on alcohol and medicine abuse among adolescents at four schools in Greater Buenos Aires
}

\author{
Silvia Cabrerizo, M.D. ${ }^{a, c}$, Silvana Varela, B.S. ${ }^{b}$, and María Inés Lutz, M.D. ${ }^{c}$
}

\begin{abstract}
Introduction. The use of alcohol and prescription drugs acquired without a prescription among adolescents has become an increasing problem at departments of toxicology. The "jarra loca" is a mix of alcoholic beverages and medicines abused by teens. In the past years, in addition to psychotropic drugs, adolescents have also added hypoglycemic drugs to the mix, which may cause neurological sequelae or even death, depending on the dose used and the duration of hypoglycemia.

Objective.To estimate the prevalence of alcohol and medicine use among 12 to 18 year-old adolescents attending four schools in the district of Tres de Febrero, province of Buenos Aires.

Material andMethods.Observational, descriptive and cross-sectional study. A survey on alcohol and medicine use was self-administered by 12 to 18 year-old adolescents from four schools in the province of Buenos Aires. During workshops, knowledge and experience were exchanged with students and infographic material was provided. Results. Nine hundred and seventy-seven surveys were completed. Of all surveyed students, $49 \%$ indicated that they have alcoholic beverages while out with their friends; $8 \%(n=78)$ admitted drinking the "jarra loca" while $49 \%$ stated that their friends did. Twenty-one students required medical care at least once following alcohol consumption, and seventeen of them had drunk the "jarra loca." Fifty-five percent of students did not know what medicines are mixed in the "jarra loca" Forty-eight percent of parents discourage alcohol consumption.

Conclusion.Forty-nine percent of students indicated that they have alcoholic beverages. In our study, $8 \%$ of surveyed students had consumed or tried the "jarra loca" once, although $49 \%$ referred that they friends did.

Key words: substance abuse, alcohol, prescribed medicines.
\end{abstract}

http:/ / dx.doi.org/10.5546/aap.2014.eng.504

\section{INTRODUCTION}

The use of alcohol and prescription medicines acquired without a prescription has become an increasing problem among adolescents. For many teens, drinking alcohol mixed with medicines allows them to socialize, but they are unaware of the risks. ${ }^{1-5}$ This situation adopts different modalities in different cities around the world. ${ }^{6-9}$ Petroianu, et al. point out that up to $12 \%$ of medical students at Universidad Federal de Minais Gerais, Brazil, use sedatives, ${ }^{6}$ Romero, et al. refer that among students at Pontificia Universidad Católica de Chile, $6.9 \%$ use benzodiazepines and $5.8 \%$ use antidepressants acquired without a prescription. ${ }^{7}$ In addition, Caamaño-Isorna, et al. revealed a high rate of medicine use among Spanish university students, most acquired without a prescription, which accounts for a different form of polydrug use. ${ }^{8}$

Mixing alcohol and medicines is commonly known as a "cocktail" or the "jarra loca." 1,2,5,10 The most commonly used medicines are benzodiazepines ${ }^{11,12}$ and their combination with alcohol increases the depressant effects of both toxic agents. ${ }^{11,12}$ In the past years, the use of hypoglycemic drugs (sulfonylureas) has also been observed; they are used to achieve the characteristic "confusion state" caused by hypoglycemia. ${ }^{10}$ One of the risks of mixing medicines in the "jarra loca" is that it is not possible to estimate the dose consumed by subjects. In certain cases, this mix caused severe intoxication, some of which had a fatal outcome and some, with irreversible neurological sequelae. ${ }^{10}$

Our aim was to estimate the profile of alcohol and medicine use among adolescents, and to implement a health educational intervention aimed at raising awareness on the risks of mixing alcohol and medicines for abuse. 


\section{OBJECTIVES}

To estimate the prevalence of alcohol and medicine use ("jarra loca") among 12 to 18 yearold adolescents attending four private and public schools in the district of Tres de Febrero, province of Buenos Aires.

To describe how adolescents access medicines for abuse, the clinical consequences of combining alcohol and medicines among adolescents, and their opinion on what their parents think of alcohol use.

\section{POPULATION AND METHODS}

The study was conducted between June 2010 and May 2011. The study population was made up of 12 to 18 year-old students from two public and two private schools, authorized by the Education Board of the district of Tres de Febrero, province of Buenos Aires.

Design: Observational, descriptive and crosssectional study.

Data collection tool or technique: A survey was first prepared. A pilot test was performed using 50 surveys, and the necessary corrections were made before starting the study. The selfadministered survey (see Annex) was given to the study enrolled students looking to establish the incidence of alcohol and medicine use, its frequency and amount, age at initiation of alcohol use, access to medicines, place of usual consumption, presence of intoxication symptoms, whether they required medical care following alcohol and medicine use, and perception of alcohol in association with having fun (considering alcohol consumption as a natural thing).

Alcohol consumption was defined as drinking, at least, one can of beer $(330 \mathrm{~mL})$ or one glass of wine $(200 \mathrm{~mL})$ or one drink $(30-50 \mathrm{~mL})$ of fernet, rum, gin, vodka, or whisky, because these are equivalent in terms of grams of alcohol that may cause acute alcohol intoxication symptoms. ${ }^{8}$

As a complementary activity, workshops were held with the participation of students from each class. During such workshops, a trigger case was used to provide information on how to react in case of suffering an acute intoxication with alcohol and medicines. At a second meeting with students, findings were discussed and infographic material was provided.

\section{Ethical considerations}

The study was approved by the Teaching and Bioethics Committee of Hospital Nacional Prof. A. Posadas. Before conducting the study, parents or legal tutors were asked to provide their consent for their children to participate, and adolescents were asked to provide their assent before taking part in the study.

\section{Statistical analyses}

The primary outcome was alcohol and medicine use expressed as frequency, and secondary endpoints were frequency and amount of consumption, age at initiation of alcohol use, access to medicines, place of usual consumption, presence of intoxication symptoms, and requiring medical care following alcohol and medicine use. In addition, sociodemographic characteristics were assessed, including age, gender and type of school, and these were expressed as dichotomized qualitative outcome measures using percentages. Primary endpoints were compared between user and non-user groups applying parametric or nonparametric tests, as applicable for each specific comparison, and a $p$ value $<0.05$ was considered statistically significant.

\section{RESULTS}

Nine hundred and seventy-seven surveys were completed. Table 1 shows the baseline characteristics of this population. Their median age was 15 years old, ranging from 12 to 20 years old. Based on the data collected from the surveys, $49 \%(\mathrm{~N}=480)$ of students admitted drinking alcoholic beverages, $11 \%$ referred that they consume energy drinks, and $40 \%$ stated that they consume non-alcoholic drinks. In terms of alcoholic beverages, $5 \%$ of students referred drinking wine and beer; $11 \%$, high grade beverages, such as vodka, gin, rum, tequila, fernet or liquor; and 33\%, a mix of alcoholic beverages, all in the context of a night out with friends. When asked about the frequency of alcohol use, its prevalence increased to $61 \%$.

Among surveyed students, $8 \%(n=78)$ referred drinking a mix of alcohol and medicines called the "jarra loca" while $49 \%(\mathrm{n} / \mathrm{N}=480 / 972)$ stated that their friends did.

Thirty-three percent $(n=297)$ indicated that they had some sort of symptoms following alcohol consumption. Of them, 251 (28\%) stated that they experienced dizziness, nausea, vomiting, headache and/or abdominal pain, while 5\% $(n=46)$ had serious symptoms, such as loss of consciousness and/or seizures.

Twenty-one students required medical care at least once following alcohol use, and seventeen of these had drunk the "jarra loca". 
In relation to parents' opinion, $20 \%(n=173)$ of adolescents indicated that their parents approved alcohol use; $48 \%(n=424)$ discouraged it; $7 \%(n=62)$ did not know that their children consumed alcohol; and $25 \%(n=211)$ had no opinion in this regard.

In the private school sample, a more frequent alcohol use was observed among 13 year-old adolescents, while in the public school sample, the higher frequency percentage $(81 \%)$ was observed in the older than 13 year-old group, a statistically significant difference (Chi : 74.51, p: 0.000).

When assessing knowledge on the medicines used in the "jarra loca" ( $\mathrm{N}=913), 55 \%$ of students said they did not know; $13 \%$ stated that they were psychotropic drugs; $7 \%$, that they were painkillers; $19 \%$ that it was a cocktail of medicines; and $7 \%$, that they were hypoglycemic agents.

In terms of where adolescents get the medicines to mix in the "jarra loca," $15 \%(\mathrm{n}=96)$ of adolescents referred that they had bought them; $6 \%(n=39)$, that they were offered to them; $5 \%(n=33)$, that they had taken them from home or from a friend's home; and $71 \%(n=448)$, that they had gotten them from a different source or that they did not know their origin.

Out of the 78 students who indicated that they consumed alcohol and medicines in the "jarra loca," $62(79 \%)$ attended a public school (Chi': $16.49, p$ : $0.000)$. In terms of age, out of the students who admitted drinking the "jarra loca" ( $\mathrm{N}=78), 69$ were older than 15 years old (Chi': 25.85, $p$ : 0.000).

Among public school students (168/310), 54\% referred that, on weekends, they had more than one can of beer $(330 \mathrm{~mL})$ or one glass of wine $(200 \mathrm{~mL})$ or one drink $(30-50 \mathrm{~mL})$ of fernet, gin, vodka, or whisky, compared to $43 \%$ (55/128) of private school students; these data were statistically significant $\left(\mathrm{Chi}^{2}: 4.56, p: 0.033\right)$.
Students who stated that they used alcohol $(\mathrm{N}=480)$ indicated that they did so to share with their friends (35\%), to have fun (22\%) or to escape from their problems (14\%); $10 \%$ said that they did not know why they used alcohol, while 19\% indicated more than one reason.

When asked if they feel that they can go out, meet with friends and have fun without using alcohol, 92\% $(n=894)$ responded positively.

In relation to the usual place of consumption, $30 \%(n=181)$ of students indicated that they do it at home or at a friend's home; $32 \%(n=191)$, at night clubs or public places; and 38\% $(n=230)$, in more than one place.

\section{DISCUSSION}

Based on these data, it appears that adolescents start drinking the "jarra loca" at an early age and its consumption increases with age, but such hypothesis should be corroborated with an analytical study. The importance of prevention in this field lays in that adolescents have no perception of the risks entailed by using alcohol and medicines so that they are able to avoid severe consequences on their health.

Although $49 \%$ of students indicated that they usually drink alcohol when meeting with friends, the prevalence of alcohol use increased to $61 \%$ when asked about consumption frequency. Such increase may be accounted for by the 13\% $(n=129)$ of adolescents who drink once a month, as they do not think of themselves as usual consumers.

These results are similar to national data that indicate an increase in the use of alcoholic beverages from $40.7 \%$ in 2005 to $61.9 \%$ in 2007, and this was observed both in males and females. ${ }^{13}$ As described in national studies, this research also evidenced alcohol abuse or

TABLE 1. Baseline characteristics of the population

\begin{tabular}{ll}
\hline Age (years) & $12-14: 36 \%(352)$ \\
n/N: $972 / 977$ & $>15: 64 \%(620)$ \\
Gender & Female: $57 \%(559)$ \\
N: 977 & - \\
School & Public: $58 \%(564)$ \\
n/N: $975 / 977$ & Private: $42 \%(411)$ \\
Alcohol use & Yes: $49 \%(480)$ \\
n/N: $972 / 977$ & - \\
Alcohol and medicine use & Yes: $8 \%(78)$ \\
n/N: $976 / 977$ & -
\end{tabular}


risky drinking on weekends, when this is more tolerated by families and the social setting. ${ }^{13-17}$

It should be noted that only $48 \%$ of parents discourage alcohol use, so health educational policies should aim at making adults become more involved in reducing adolescent alcohol use.

It appears that there is a change in the pattern of alcoholic beverage use among adolescents: from the Mediterranean wine-making model, where consumption was related to family and eating tradition, to an Anglo-Saxon model, where consumption is occasional but points to an acute intoxication, ${ }^{17}$ with a preference for distilled beverages, such as tequila and vodka, as reflected in our results.

The consumption of the "jarra loca" may have been underreported probably because adolescents are afraid of revealing such information in the school setting since, unlike the "jarra loca" they think alcohol is not a drug. This has been consistently observed in student workshops and has also been evidenced in national studies conducted in secondary schools which showed that adolescents do not perceive alcohol abuse as a potential problem. ${ }^{16}$

Most adolescents are unaware of the pharmacological action of medicines mixed with alcoholic beverages, and one of the greatest risks is that $6 \%$ of students admitted to using hypoglycemic drugs or a mix of pills, including hypoglycemic drugs.

Our study evidences how easy it is for adolescents to access such medicines and their lack of awareness regarding the use of medicines with alcohol. As per our study, most visits to the National Poison Control Center that required medical care were in relation to drinking the "jarra loca" and affected youth aged between 18 and 25 years old, which is consistent with national studies. Some of the recorded cases resulted in death, while others developed neurological sequelae associated with hypoglycemic agents. ${ }^{10}$ It is worth noting that most of the adolescents who admitted that they required medical care due to severe symptoms had consumed the "jarra loca"

One of the limitations of our study is that the sample was selected by convenience, based on a meeting with the school district authorities, who had convened school directors, and such directors were the ones whose schools were included in the study. Results cannot be generalized because we are unaware of the problems observed in other schools in the same area, to which we had no access. Another limitation is the bias implied by self-administered surveys.

One of the strengths of our study is that $100 \%$ of students present that day agreed to participate and were willing to receive the survey reports and discuss the subject. It should be noted that the student workshops allowed them to tell their experience and reflect on the risks to which them or their friends are exposed under the influence of alcohol. School teachers were also thankful for the health team visit to their schools, and this reveals the need for a collective approach to this problem.

Based on the study design, it was not possible to establish which factors lead adolescents to mix alcohol and medicines or to address family or personal situations that might lead them to do it, and this should be investigated using a more complex design, which is beyond our study's scope.

This study discloses that this has become a common problem among secondary school students, and systematic interventions should be implemented in this group.

\section{CONCLUSION}

Of all surveyed students, 51\% referred that they do no drink alcohol, while $49 \%$ indicated that they usually drink alcohol when meeting with friends; however, the prevalence of alcohol use increased to $61 \%$ when asked about consumption frequency. In this regard, $8 \%$ referred drinking or having tried the "jarra loca" while $49 \%$ stated that their friends did. Of the students who had symptoms as a result of alcohol use, $5 \%$ experienced loss of consciousness and/or seizures.

\section{REFERENCES}

1. Narváez A. Los jóvenes y la noche. Buenos Aires: Sociedad Argentina de Pediatría; 2011. Available at: http:/ / www. sap.org.ar/docs/institucional/jovenes.pdf. [Accesed:July 12, 2012].

2. Míguez HA. Alcohol y disponibilidad en la fiesta adolescente. Trastoradict 2009;11(1):39-43.

3. Míguez HA. El espejo de Erised. Determinaciones sociales del abuso epidémico de alcohol. Ed. Programa de Epidemiología Psiquiátrica. Buenos Aires, 2005. Available at http:/ / miguezhugo.com.ar/ERI/eri.pdf. [Accesed: July 6, 2012].

4. Varela A, Pritchard ME. Peer influence: use of alcohol, tobacco, and prescription medications. J Am CollHealth2011;59(8):751-6.

5. Braschi ME, Santos IJ. Drogas y adolescencia. Rev HospNiños B Aires 2006;48(220):281-91.

6. Petroianu A, Reis DC, Cunha BD, Souza DM. Prevalence of alcohol, tobacco and psychotropic drug use among medical students at the Universidade Federal de Minas Gerais. 
RevAssocMedBras2010;56(5):568-71.

7. Romero MI, Santander J, Hitschfeld MJ, Labbé M, et al. Consumo de sustancias ilícitas y psicotrópicos entre los estudiantes de medicina de la Pontificia Universidad Católica de Chile. RevMed Chile 2009;137:459-65.

8. Caamaño-Isorna F, Mota N, Crego A, Corral M, et al. Consumption of medicines, alcohol, tobacco and cannabis among university students: a 2-year follow-up. Int J PublicHealth2011;56(3):247-52.

9. Hammond D, Ahmed R, Yang WS, Brukhalter R, et al. Illicit substance use among Canadian youth: trends between 2002 and 2008. Can J Public Health 2011;102(1):7-12.

10. Cabrerizo S, Docampo PC. Alcohol y mezcla de fármacos: modalidad de abuso frecuente. Arch Argent Pediatr2010;108(5):e111-3.

11. Yip L. Ethanol. En: Flomenbaum NE, Goldfrank LR, Hoffman RS, et al., eds. Golfrank'stoxicologic emergencies. 8th ed. New York: McGraw-Hill; 2006. Págs.1147-61.

12. Ellenhorn MJ. Alcohols and glycols. En: Ellenhorn MJ, Schonwald S, Ordog G, et al., eds. Ellenhorn's medical toxicology: Diagnosis and treatment of human poisoning. $2^{\text {nd }} \mathrm{ed}$. Baltimore: Williams and Wilkins; 1997. Págs.1127-45.

13. Argentina. SEDRONAR. Estudio Nacional sobre consumo en estudiantes de enseñanza media. Informe preliminar
2011: Dirección Nacional del Observatorio Argentino de Drogas. Available at: http:/ /www.marcelogastaldi.com. ar/archivos/novedades_MG/archivos/12-05-08-Estudio NacionalConsumoEstudiantesEnsMedia.pdf. [Accesed: August 10, 2012].

14. Instituto Nacional de Estadística y Censos. Anexo a los resultados de la Encuesta Nacional sobre Prevalencias de Consumo de Sustancias Psicoactivas 2008 - ENPreCoSP-2008. Buenos Aires, 2008. Available at: http:/ /www. indec.gov.ar/ftp/cuadros/publicaciones/anexo_enprecosp_29_07_08.pdf. [Accesed: June 27, 2014].

15. Argentina. Ministerio de Salud de la Nación. Sistema de Vigilancia Epidemiológica en Salud Mental y Adicciones. Algunos datos sobre el consumo de alcohol en Argentina. Año 2011. Buenos Aires, 2011. Available at: http:/ / www. msal.gov.ar/saludmental/images/stories/info-equipos/ pdf/4-algunos-datos-sobre-el-consumo-de-alcohol.pdf. [Accesed: August 10, 2012].

16. Schmidt V. Predictores de abuso de alcohol en adolescentes. Mitos versus evidencia empírica. Anuinvestig (FacPsicolUniv B Aires) 2007;14:229-39.

17. Míguez HA. Patrones culturales de la alcoholización social en estudiantes bonaerenses. Vertex (B Aires) 2009;XX(87):325-8. 
ANNEX

SURVEY

\section{Mark with an $\mathrm{X}$ the statement that applies to you.}

Age:

Gender:

Female

Male

1. What do you usually drink when meeting with friends?

Wine

Energy drinks (Speed, etc.).

BeerWater, juice or carbonated soft drinks.

Vodka, gin, whisky, rum, tequila, grappa.

Others: fernet, Gancia, liquors.

2. How many alcoholic beverages do you drink when going out on weekends?

I do not drink alcohol.

1 can of beer $(330 \mathrm{~mL})$ or 1 glass of wine $(200 \mathrm{~mL})$ or 1 drink $(30-50 \mathrm{~mL})$ of fernet, rum, gin, vodka, whisky.

More than 1 can of beer $(330 \mathrm{~mL})$, more than 1 glass of wine $(200 \mathrm{~mL})$ or more than 1 drink (30-50 mL) of fernet, rum, gin, vodka, whisky.

3. How many alcoholic beverages do you usually drink (every day)?

I do not drink alcohol.

Up to 1 can of beer $(330 \mathrm{~mL})$ or 1 glass of wine $(200 \mathrm{~mL})$ or 1 drink (30-50 mL) of fernet, rum, gin, vodka, whisky.

More than 1 can of beer $(330 \mathrm{~mL})$, more than 1 glass of wine $(200 \mathrm{~mL})$ or more than 1 drink (30-50 mL) of fernet, rum, gin, vodka, whisky.

4. How often do you usually drink alcoholic beverages?

I do not drink alcohol.

Every day.

Twice or three times a week.

Once a week.

Once every 15 days.

Once a month.

5. At what age did you start drinking alcohol?

6. Have you ever mixed pills or medicines with alcohol?

Yes.

No.

7. At what age did you start mixing alcohol and medicines?

8. Do you know if your friends have ever tried or used a mix of alcohol and pills or medicines?

Yes.

No.

9. Do you know what those medicines are for?

I do not know what they are for.

Tranquilizers (sleeping pills). 
Muscle relaxants.

Hypoglycemic drugs (medication to control blood sugar levels or diabetes).

Psychotropic drugs.

Painkillers (pain medication).

10. If you have tried mixing alcohol and medicines, how did you get the medicines?

From home or a friend's home.

They were offered to me.

I bought them.

Other.

I do not know.

11. Where do you usually drink alcohol?

I do not drink alcohol.

Home or a friend's home.

Night club.

School.

Public place (park, club, street, etc.).

12. Have you ever had any of these symptoms following alcohol use?

Dizziness, nausea, vomiting, headache and/or abdominal pain. Yes No

Loss of consciousness (not recalling what happened, falling asleep on the street, etc.)

or seizures. Yes No

I have never had any symptom. Yes No

13. Have you ever required medical care or been admitted to an emergency department in a health facility after drinking alcohol?

Never.

Once.

Twice or three times.

More than three times.

14. Have you ever required medical care or been admitted to an emergency department in a health facility after mixing alcohol and medicines?

Never.

Once.

Twice or three times.

More than three times.

15. Can you go out, meet with friends and have fun without using alcohol?

Yes.

No.

16. If you drink alcohol, what do your parents think about it?

They approve it.

They discourage it.

They have no opinion.

They do not know.

17. If you drink alcohol, do your parents know?

Yes.

No.

18. Why do you use alcohol and/or medicines?

I do not use alcohol or medicines.

To have fun.

Because others do.

To share with my friends.

To escape from my problems.

I do not know why. 